\title{
ПРЕЖДЕВРЕМЕННАЯ МУЖСКАЯ СМЕРТНОСТЬ И ЭКОНОМИЧЕСКОЕ БЛАГОСОСТОЯНИЕ ДОМохозяЙСТВ
}

\section{ПОЛИНА КУЗНЕЦОВА}

\begin{abstract}
В работе на основе на данных Российского мониторинга экономического состояния и здоровья за 2001-2019 г2. (РМЭ3) оценивается влияние смерти членов семьи, в том числе мужчин трудоспособного возраста, на благосостояние домохозяйств, в которых проживали умершие. Показано, что даннье РМЭЗ, несмотря на определенную систематическую ошибку при регистрации смертей респондентов, могут быть использованы для оченки смертности мужчин и лиц трудоспособного возраста.

Показано, что в год смерти члена домохозяйства средние реальные подушевые доходы его семьи растут, m. е. эффект от снижения размера семьи оказывается сильнее эффекта от падения общих доходов. Дело в том, что экономические проблемы домохозяйства, связанные с потерей работоспособных членов семьи, начинаются не в год смерти, а заметно раньше. В связи с этим был рассмотрен более широкий временной диапазон, от 5 лет до смерти члена семьи до 5 лет после нее. Регрессионный анализ процессов попадания в бедность и выхода из нее показал, что смерть членов семьи оказывает негативное влияние на благосостояние других членов домохозяйства. В случае смерти мужчины трудоспособного возраста домохозяйства сталкиваются с повыменными рисками попадания в бедность в течение 1-5 лет до и после этого события.
\end{abstract}

Ключевые слова: смертность, панельные данные, бедность, анализ длительности, структура домохозяйств, РМЭЗ.

\section{ВВЕДЕНИЕ}

В работе рассматривается взаимосвязь мужской смертности в трудоспособных возрастах и благосостояния российских домохозяйств. Феномен высокой мужской смертности в России широко известен и хорошо изучен (Shkolnikov et al. 2013; Grigoriev et al. 2020). Преждевременная мужская смертность и высокий гендерный разрыв в продолжительности жизни в значительной мере объясняются большей распространенностью среди мужчин нерациональных стереотипов поведения, таких как курение, потребление алкоголя и недостаточное внимание к собственному здоровью (Андреев 2001; Kossova et al. 2020; Denisova 2010).

ПОЛИНА ОЛЕГОВНА КУЗНЕЦОВА (polina.kuznetsova29@gmail.com), РОССИЙСКАЯ АКАДЕМИИ НАРОДНОГО ХОЗЯЙСТВА И ГОСУДАРСТВЕННОЙ СЛУЖБЫ ПРИ ПРЕЗИДЕНТЕ РОССИЙСКОЙ ФЕДЕРАЦИИ, РОССИЯ.

СТАТЬЯ ПОДГОТОВЛЕНА В РАМКАХ ВЫПОЛНЕНИЯ НАУЧНО-ИССЛЕДОВАТЕЛЬСКОЙ РАБОТЫ ГОСУДАРСТВЕННОГО ЗАДАНИЯ РАНХИГС.

СТАТЬЯ ПОСТУПИЛА В РЕДАКЦИЮ В ИЮНЕ 2021 Г. 
Будучи весьма распространенной в трудоспособных возрастах, мужская смертность оказывает непосредственное влияние на структуру домохозяйств, увеличивая представленность в ней неполных семей с детьми (Захаров, Чурилова 2013) и домохозяйств, в которых проживают одинокие женщины. Неполные семьи с несовершеннолетними детьми традиционно относятся к числу наиболее уязвимых с точки зрения как доходной, так и депривационной бедности (Гришина 2018). Ответ на вопрос о том, как влияет смерть члена семьи на благосостояние домохозяйств без несовершеннолетних детей, не столь очевиден.

Негативные события в жизни домохозяйств, к числу которых наряду с разводом относится смерть члена семьи, являются важным направлением формирования бедности (Аникин, Тихонова 2014). Сведения о том, в какой степени вклад мужчин трудоспособного возраста является определяющим для доходов домохозяйств, в которых они проживают, представлены в таблице 1. С ростом размера семьи вклад трудоспособных мужчин в доходы становится все больше по сравнению с другими членами домохозяйства. Так, например, в 2019 г. для домохозяйств из двух человек вклад мужчин в доходы домохозяйств, в которых они проживали, примерно соответствовал аналогичному вкладу женщин. В то же время для семьи из четырех человек доля доходов мужчин в возрасте 15-59 лет составляла 57\% семейных доходов, что заметно выше, чем для женщин в возрасте 15-54 лет и пожилых членов домохозяйств.

Таблица 1. Вклад членов семьи в зависимости от пола и возраста в доходы домохозяйств (для домохозяйств, в которых проживают члены семьи соответствующего пола и возраста), \% доходов домохозяйств

\begin{tabular}{l|c|c|c|c|c}
\hline & $\begin{array}{c}1 \\
\text { человек }\end{array}$ & $\begin{array}{c}2 \\
\text { человека }\end{array}$ & $\begin{array}{c}3 \\
\text { человека }\end{array}$ & $\begin{array}{c}4 \\
\text { человека }\end{array}$ & $\begin{array}{c}5 \text { и более } \\
\text { человек }\end{array}$ \\
\hline Доля доходов мужчин в возрасте 15-59 лет & 100 & 56 & 56 & 57 & 53 \\
$\begin{array}{l}\text { Доля доходов женщин в возрасте 15-54 года } \\
\text { Доля доходов мужчин в возрасте от 60 лет и }\end{array}$ & 100 & 56 & 46 & 39 & 36 \\
$\begin{array}{l}\text { старше } \\
\text { Доля доходов женщин в возрасте от 55 лет и } \\
\text { старше }\end{array}$ & 100 & 53 & 40 & 32 & 23 \\
\hline
\end{tabular}

В настоящем исследовании представлена попытка автора взглянуть на влияние, которое оказывает смерть одного из членов семьи на благосостояние оставшихся членов домохозяйства. В отличие от работы (Denisova 2010), в которой смерть респондента рассматривается как зависимая переменная и определяются факторы, оказывающие на нее влияние, мы будем изучать эту взаимосвязь в обратном направлении: в фокусе данной работы благосостояние домохозяйств, на которое влияет (или, возможно, не влияет) уход из жизни кого-то из взрослых членов семьи - мужчин и женщин разного возраста.

Основой проведенного эмпирического исследования стали ретроспективные данные РМЭ3 с 2001 по 2019 г. Статья структурирована следующим образом. Сначала представлены обзор литературы и обсуждение проблем, возникающих при анализе смертности с помощью данных социологического обследования. Далее описаны данные и методика исследования. В результативной части статьи представлены результаты регрессионного анализа взаимосвязи смертности и экономического благосостояния домохозяйств. В заключении приведены краткие выводы. 


\section{ОБЗОР ЛИТЕРАТУРЫ}

Гипотезы о событиях, оказывающих влияние на попадание в бедность и выход из нее, основаны на теории о человеческом капитале Г. Беккера и Дж. Минсера (Becker 2009а; Mincer 1993) и теории спроса на детей Г. Беккера (Becker 2009b). Эти 2 теории определяют основные факторы доходов и размера домохозяйств, из которых складываются подушевые доходы, в том числе пол, возраст, уровень человеческого капитала членов семьи и ее демографический состав (McKernan, Ratcliffe 2005).

Существует множество эмпирических исследований, изучающих факторы бедности. Наиболее распространенный подход к изучению бедности предполагает использование для оценки масштабов бедности данных на конкретный момент, для данного временного среза. В такой эконометрической модели вероятность бедности в данный момент времени рассматривается как функция текущих значений различных индивидуальных и домохозяйственных характеристик (т.е. без учета изменения факторов во времени). Использование этого интуитивно и методически простого подхода дает возможность ответить на ряд принципиально важных вопросов, в том числе, какова распространенность бедности среди различных социально-демографических групп. Однако данный метод не учитывает изменения, которые происходят во времени. Для этого необходим динамический анализ бедности с использованием панельных данных.

В современной научной литературе представлен широкий набор методов количественной оценки взаимосвязи смертности и благосостояния во времени. Для выявления последствий событий в жизни домохозяйства (развод, смерть одного из членов семьи) в том числе могут быть использованы такие методы, как анализ выживаемости в некотором состоянии при наступлении событий (survival analysis), впервые примененный к изучению бедности в работе (Bane, Ellwood 1986); линейная панельная регрессия с фиксированными эффектами, включающая наблюдения за несколько лет до и после экспериментального события, такого, например, как смерть супруга, развод, прекращение совместного проживания и др. (Leopold 2018); пробит- или логит-модели для поиска факторов вероятности быть бедным, условной вероятности быть хронически бедным, будучи бедным, а также вероятности попадания в бедность и выхода из нее (Lindquist, Lindquist 2012); усовершенствованный метод с учетом старения панели данных (Cappellari, Jenkins 2002; Fusco, Islam 2012) и др.

Результаты эмпирических исследований в различных странах говорят о том, что бедность - явление неоднородное. В развитых странах более распространена эпизодическая бедность, когда домохозяйства испытывают дефицит доходов лишь очень короткое время, что свойственно, например, молодежи (Bane, Ellwood 1986; Lindquist, Lindquist 2012; Fusco, Islam 2012; Jenkins, Van Kerm 2014). Однако некоторые группы, включая детей и представителей этнических и национальных меньшинств, с высокой вероятностью долго пребывают в состоянии бедности (Cappellari, Jenkins 2002). В развивающихся странах выйти из состояния бедности сложнее, и потому наиболее распространенной является хроническая бедность (Haq, Arif 2004; Ozdamar, Giovanis 2017; Yamauchi, Buthelezi, Velia 2006). 
В странах с высоким уровнем социального развития дети, как правило, защищены экономически от таких серьезных событий, как болезнь или смерть родителя/родителей. Так, например, в Швеции дети, потерявшие родителей, имеют право на щедрую пенсию от государственной системы социального обеспечения; кроме того, в стране широко распространено частное страхование жизни, охватывающее 2/3 населения страны (Lindquist, Lindquist 2012). Как следствие, существенно сильнее, чем смертность или заболеваемость, способствуют попаданию в бедность распад семьи или потеря родителями работы.

В данном исследовании нас интересует, как смертность влияет на благосостояние, однако, как следует из теории спроса на здоровье М. Гроссмана (Grossman 1972), взаимосвязь между здоровьем и доходами и, как следствие, между смертностью и доходами, является двусторонней. Существует возможность обратной связи между доходами и смертностью, когда ухудшение благосостояния домохозяйства оказывает негативное влияние на здоровье членов семьи и в дальнейшем становится причиной смерти. B работе (Duleep 1986) на американских данных показано, что низкий доход значимо повышает риск мужской смертности, причем наличие дополнительного влияния доходов на риски ухудшения здоровья и инвалидности способствует усилению этой негативной взаимосвязи. Об этой двойственности упоминается в работе (Jusot 2006), в которой исследуется характер взаимосвязи между доходами и смертностью во Франции. Результаты показывают, что риск смерти сильно коррелирует с уровнем дохода независимо от профессионального статуса.

В то же время в ряде эмпирических исследований было показано, что влияние доходов на смертность в отличие от влияния доходов на здоровье как минимум невелико (Snyder, Evans 2006; Evans, Moore 2011; Ahammer, Horvath, Winter-Ebmer 2015). Чем это можно объяснить? Наличие и масштабы социально-экономического градиента в здоровье и смертности зависят от эффективности разных направлений национальных систем здравоохранения. В случае смертности социально-экономический градиент в большей степени обусловлен эффективностью лечения острых состояний здоровья, в то время как взаимосвязь между доходами и здоровьем в основном определяется профилактикой и своевременной диагностикой заболеваний (Adams et al. 2003).

Другим близким по тематике к данной работе направлением исследований является анализ благосостояния вдов. Основной массив работ в этом направлении выполнен на данных развитых стран и потому сконцентрирован на проблемах пожилых людей (от 65 лет и старше). Наиболее популярна данная тема была в последней четверти XX века, когда проблема бедности вдов в западных странах стояла существенно острее. Начиная с 1990-х годов уровень бедности среди вдов стал резко снижаться, чему способствовали повышение уровня образования женщин, рост их рабочего стажа, изменение структуры брака (женщины с более высоким социально-экономическим статусом стали чаще состоять в браке, чем женщины с более низким статусом), а также рост социальной поддержки (Munnell, Eschtruth 2018; Munnell, Sanzenbacher, Zulkarnain 2019).

Ряд исследований благосостояния вдов выполнен на данных африканских стран, где вдовство вызвано преждевременной мужской смертностью, прежде всего в результате 
эпидемии ВИЧ. Смерть кормильца снижает шансы детей, в особенности девочек, продолжать образование (Yamauchi, Buthelezi, Velia 2006). Овдовевшие женщины чаще выходят на работу, что в свою очередь может приводить к сокращению времени на работу по дому и воспитание детей и тем самым ухудшать условия для формирования человеческого капитала у осиротевших детей (Mather 2011).

Данное исследование отличается от большинства работ по теме смертности и доходов. Мы изучаем событие смерти в домохозяйстве, что само по себе является редким объектом исследования. Также важную роль играет российская специфика последствий смерти кого-то из членов семьи. В развитых странах умершим мужчинам в подавляющем большинстве наследуют пожилые женщины и соответственно фокус исследований по теме смещен в сторону пенсионного и социального обеспечения и других проблем пожилых. Нас же в силу особенностей анализа смертности на данных социологического опроса в большей степени интересуют последствия смерти членов семьи трудоспособного возраста. В беднейших развивающихся странах овдовевшие женщины существенно моложе, чем в развитых странах Запада, но тем не менее проблемы, с которыми они сталкиваются, существенно отличаются от проблем российских домохозяйств, переживших смерть мужчины трудоспособного возраста.

Для данного исследования наиболее методологически близкими являются 2 работы Ирины Денисовой, посвященные анализу факторов мужской смертности (Denisova 2010), а также выявлению характеристик, способствующих попаданию и выходу домохозяйств из бедности (Denisova 2007). Оба исследования были выполнены на панельных данных Российского мониторинга экономического положения и здоровья населения (РМЭЗ); при регрессионных оценках использован анализ длительностей. Также в работе (Denisova 2010) подробно представлена аргументация в пользу использования данных лонгитюдного социологического исследования для изучения смертности.

По результатам обзора литературы был определен перечень потенциальных факторов для использования в эконометрическом анализе. Наряду с социальнодемографическими характеристиками домохозяйства, применявшимися в работе И. Денисовой (перечислены в Таблице 2 ниже), это переменные, содержащие информацию о времени до и после смерти членов семьи. Вслед за немецким исследованием краткосрочных и долгосрочных последствий развода (Leopold 2018) мы рассматриваем 5 временных интервалов: 1) 5-3 года до смерти члена семьи; 2) 2-1 года до смерти; 3) год смерти; 4) через 1-2 года после смерти; 5) через 3-5 лет после смерти.

\section{АНАЛИЗ СМЕРТНОСТИ С ИСПОЛЬЗОВАНИЕМ ДАННЫХ РМЭЗ: ОСНОВНЫЕ ПРОБЛЕМЫ И ОГРАНИЧЕНИЯ}

Для того чтобы ответить на главный вопрос исследования (как влияет смерть члена семьи на благосостояние домохозяйства), нужны особые данные о смертности. Агрегированные данные официальной статистики предоставляют подробную информацию о ее возрастной структуре, вкладе различных причин смерти, региональной составляющей и так далее, но 
не позволяют узнать, в каких семьях проживали умершие и как семья и ближайшие родственники умершего жили до и после их смерти.

Гипотезы исследования предполагают подключение к данным о смертности информации об индивидуальных характеристиках умерших и членов их семей. Официальные данные о смертности в данном случае использованы быть не могут, поскольку содержат очень скупую информацию об умерших (пол, возраст, тип населенного пункта и причина смерти). Интересующая нас информация об индивидуумах и домохозяйствах, в которых они проживают, содержится в национальном репрезентативном обследовании РМЭЗ, однако при использовании данных социологических опросов встает вопрос, насколько надежными являются оценки смертности, полученные на их основе.

Могут ли данные РМЭЗ использоваться для анализа смертности? Насколько точно факт смерти респондента фиксируется в обследовании? Вообще говоря, ответы на эти вопросы неочевидны. В международной исследовательской практике при анализе смертности активно используют индивидуальные характеристики умерших, но также и дополнительные источники данных для уточнения смертности, например Национальный индекс смертности (National Death Index) в США (Mehta, House, Elliott 2015) или данные национального регистра смертности в Швеции (Sydén, Landberg 2017). В РМЭЗ смертность в домохозяйствах, исчезнувших из выборки, не уточняется, что приводит к систематической ошибке (Denisova 2010; Чернышева, Фурманов 2013). В настоящем исследовании в том числе предпринята попытка ответить на вопрос, могут ли данные РМЭЗ быть использованы для анализа смертности населения в целом и отдельных половозрастных групп.

Более ранние работы свидетельствуют, что это возможно. Так, в работе (Perlman, Bobak 2008) без дальнейших уточнений отмечается, что коэффициенты смертности по данным РМЭЗ в целом соответствуют официальным показателям. Более подробное сравнение коэффициентов смертности по данным РМЭЗ и по официальной статистике Росстата представлено в исследовании микрофакторов смертности (Denisova 2010). По оценкам автора, в основном из поля зрения интервьюеров РМЭЗ исчезают одиноко проживающие респонденты, большую часть которых составляют пожилые люди, в связи с чем коэффициенты смертности, рассчитанные по данным РМЭЗ, в 1994-2007 гг. были на 25-30\% ниже официальных.

Мы сравнили коэффициенты смертности по РМЭЗ с данными официальной статистики (рисунок 1). Как видно, РМЭЗ смертность мужчин и женщин всех возрастов заметно недооценивает (рисунок 1, графики в первом ряду). Если же ограничиться только респондентами трудоспособного возраста (рисунок 1, нижний ряд графиков), то уровень различий существенно снижается.

На рисунке 1 также хорошо различимы периоды постепенного роста смертности, измеренной на основе данных РМЭЗ, соответствующие старению базы, за которыми следуют моменты ее резкого снижения, вызванные пополнением базы, когда в выборку включаются новые домохозяйства. Также следует отметить, что в последнее время кривые смертности по Росстату и смертности, рассчитанной по данным РМЭЗ, сближаются. 
Важным ограничением РМЭЗ является систематическая ошибка в оценке смертности одиноких респондентов. Так как информация о смерти члена семьи собирается со слов других членов домохозяйства, «случаи смерти членов домохозяйства в домохозяйствах, состоящих из одного или двух человек (особенно если они возглавляются пожилыми людьми), не учитываются в обычной процедуре обследования, поскольку данные домохозяйства не найдены по адресу» (Denisova 2010: 341)). Эффект такого занижения смертности хорошо виден на рисунке 1. Недооценка женской смертности в целом при неплохом качестве аналогичных оценок в трудоспособном возрасте говорит о том, что основные расхождения происходят в старших возрастах. Можно предположить, что основу домохозяйств небольшого размера, «исчезнувших» из зоны видимости обследования в результате смерти респондентов, составляют одинокие женщины старших возрастов.
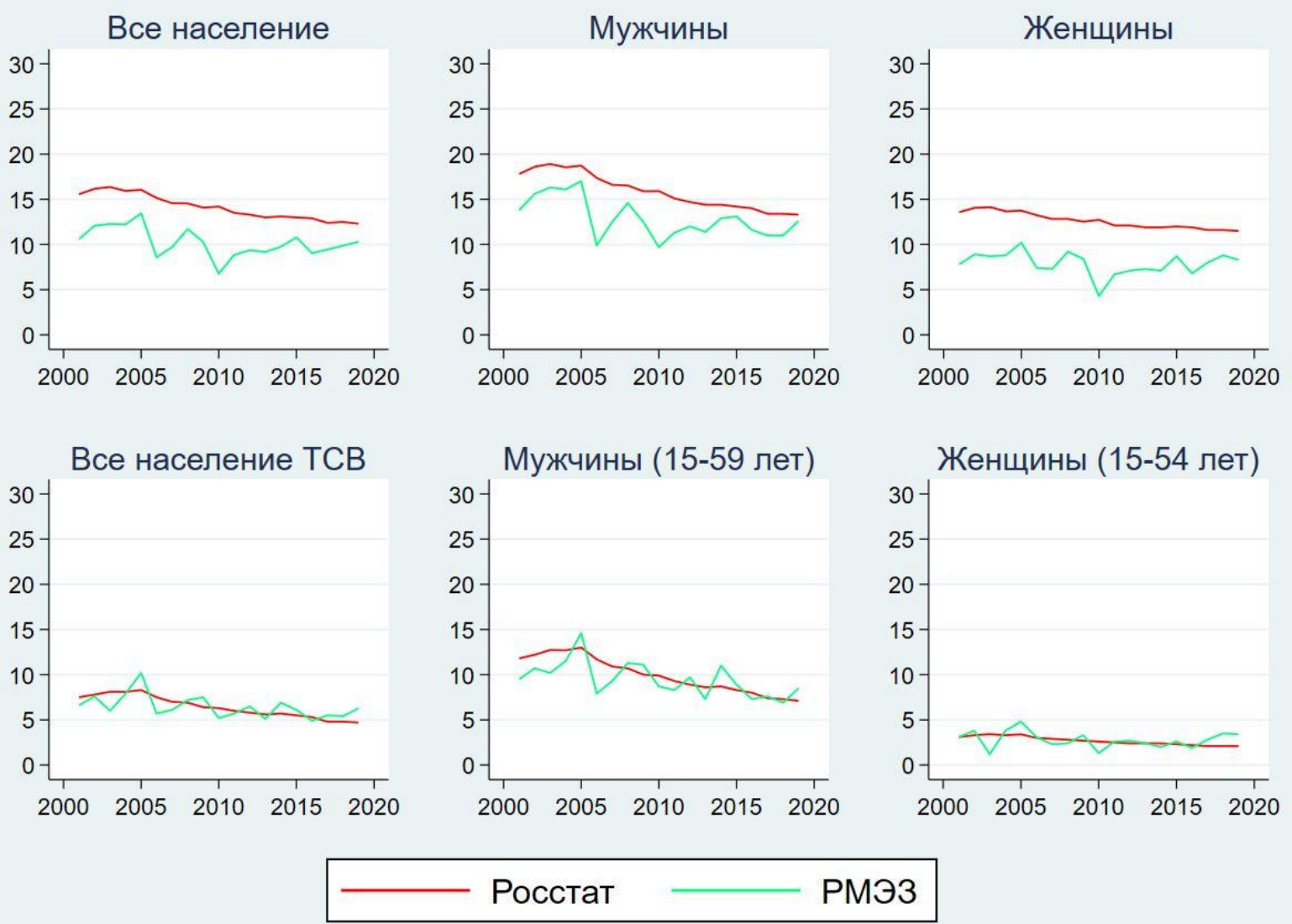

\section{Рисунок 1. Коэффициенты смертности (официальная статистика и расчеты по данным РМЭЗ) для различных возрастных групп, 2001-2019}

Источник: Расчеты автора по данным РМЭЗ и данные официальной статистики.

Примечание: ТСВ - в трудоспособном возрасте.

Учитывая особенности сбора данных о смерти респондентов в РМЭЗ, можно за счет определенного ограничения выборки добиться существенного улучшения точности оценки смертности. Во-первых, рациональным выглядит включение в выборки данных, начиная с 2001 г., когда была существенно уточнена переменная с информацией о причине отсутствия члена домохозяйства в текущем раунде. Кроме того, переход к рассмотрению 
трудоспособных возрастов также существенно приближает оценки смертности по РМЭЗ к официальной статистике.

\section{ДАННЫЕ И МЕТОДИКА}

В качестве эмпирической базы исследования были использованы данные Российского мониторинга экономического положения и здоровья населения (РМЭЗ НИУ ВШЭ). Мы использовали данные несбалансированной панели 2001-2019 гг., а также для того, чтобы учесть различия в двух последних десятилетиях, отдельно рассматривали выборки 2001-2009 гг. и 2011-2019 гг. Использование этих трех выборок позволяет получить представление о динамике благосостояния домохозяйств различного типа в различные экономические периоды: быстрый экономический рост начала и середины 2000-х годов, глобальный кризис 2008 г. и посткризисная адаптация 2009-2013 гг., а также последствия событий 2014 г., выразившиеся, в частности, в снижении и стагнации реальных доходов населения.

Переменная «Смерть одного из членов домохозяйства» представлена в РМЭЗ с помощью трех переменных, включающих: 1) 4 варианта ответа (1995-2000 гг.); 2) около 70 вариантов ответа, большинство из которых уточняют причину смерти (20012008 гг.); 3) около 100 содержательных вариантов ответа, большинство из которых уточняют причину смерти (2009-2018 гг.). В расчетах использовали данные РМЭЗ, начиная с 2001 г., т. е. для второго и третьего вариантов переменной.

С целью учета различий в региональных ценах использовали корректирующий коэффициент, равный соотношению региональных прожиточных минимумов и прожиточного минимума в эталонном регионе. В качестве эталонного был выбран регион с прожиточным минимумом, близким к медианному (Саратовская область). Для перехода к реальным ценам в панельной выборке (рассматривали период с 2001 по 2019 г.) применяли коэффициент инфляции, полученный на основе динамики прожиточного минимума в эталонном регионе.

Попадание домохозяйств в бедность и их выход из нее определялся с помощью показателя доходной бедности. Бедным считалось домохозяйство, чьи среднедушевые доходы были ниже регионального прожиточного минимума за Ш квартал рассматриваемого года.

В качестве независимых переменных, объясняющих изменение уровня благосостояния домохозяйств, при регрессионном анализе были рассмотрены несколько групп характеристик демографического состава семьи, качества человеческого капитала членов домохозяйства и их статуса на рынке труда, а также индивидуальных характеристик главы семьи. Здоровье респондентов определяли на основе вопроса о его самооценке. Мы считали, что у респондента плохое здоровье, если на вопрос «Скажите, пожалуйста, как Вы оцениваете Ваше здоровье?» был дан ответ «Плохое» или «Очень плохое». 
Для определения взаимосвязи благосостояния семьи и события смерти кого-то из членов домохозяйства в регрессионный анализ были включены переменные, содержащие информацию о непосредственном событии смерти и о периодах времени до и после него.

Данные РМЭЗ содержат подробную информацию о родственных связях респондентов, что позволяет использовать при расчетах разнообразные типологии домохозяйств (Абанокова 2015; Denisova 2007). В ходе регрессионного анализа мы будет использовать типологию домохозяйств, основанную на половозрастных характеристиках главы семьи. Рассматривали 4 типа домохозяйств, а именно возглавляемые: 1) мужчиной трудоспособного возраста; 2) женщиной трудоспособного возраста; 3) мужчиной пенсионного возраста; 4) женщиной пенсионного возраста. Главой семьи считается респондент с наиболее высокими индивидуальными доходами. При отсутствии сведений о доходах главой семьи считается референтный член домохозяйства - лицо, наиболее осведомленное о составе и бюджете домохозяйства, с чьих слов заполняется домохозяйственная анкета обследования. В качестве референтной категории рассматривались домохозяйства, возглавляемые мужчинами трудоспособного возраста.

Регрессионный анализ процессов входа и выхода из бедности был осуществлен с использованием полупараметрической модели Кокса в дискретном времени (Сox 1972; Klein, Moeschberger 2003). Для дискретной случайной величины $T$, отражающей продолжительность состояния бедности или небедности, функция риска $\lambda$ определяется следующим образом:

$$
\lambda(t)=P(T=t \mid T \geq t) .
$$

Для состояния, продлившегося $t$ лет, эта функция отражает вероятность его прекращения в течение ближайшего года. Дискретная модель Кокса так задаёт функциональную форму связи риска и объясняющих переменных (Klein, Moeschberger 2003: 259):

$$
\frac{\lambda(t, X, \beta)}{1-\lambda(t, X, \beta)}=\frac{\lambda_{0}(t)}{1-\lambda_{0}(t)} \exp \left(\beta^{\prime} X\right)
$$

где $X$ - вектор объясняющих переменных, $\beta$ - оцениваемые коэффициенты, $\lambda_{0}(t)-$ базовая функция риска (отражает риск при отсутствии воздействия объясняющих переменных, т. е. при $\left.\beta^{\prime} X=0\right)$. Вектор $X$ содержит информацию о социальнодемографическом составе домохозяйства, а также сведения о времени смерти членов семьи различного возраста.

Данные РМЭЗ о динамике бедности являются неполными, что обусловлено усечением слева, интервальным цензурированием и цензурированием справа. Усечение слева происходит в тех случаях, когда на момент попадания в выборку домохозяйства уже находились в состоянии небедности/бедности. Цензурирование справа наблюдается для незавершенных эпизодов перехода в бедность/небедность, когда домохозяйство так и осталось небедным/бедным. Применение методов анализа длительности позволяет решить проблему смещенности оценок, возникающую как вследствие усечения слева, так и цензурирования справа (Ратникова, Фурманов 2014). Интервальное цензурирование происходит из-за того, что в ряде случаев в наблюдениях за 
домохозяйством имеются пропуски, из-за которых не удается понять, в какой именно момент произошло интересующее нас событие. Незначительное количество наблюдений с пропусками было удалено.

При моделировании попадания домохозяйств в бедность мы отсчитываем время от момента, когда домохозяйство оказывается в зоне риска изучаемого события. Это соответствует моменту, когда значение переменной «домохозяйство является бедным» оказывается равным 0. Переход в бедность, соответствующий концу эпизода небедности, происходит, когда значение переменной меняется с 0 на 1. Выход из бедности моделировали аналогично.
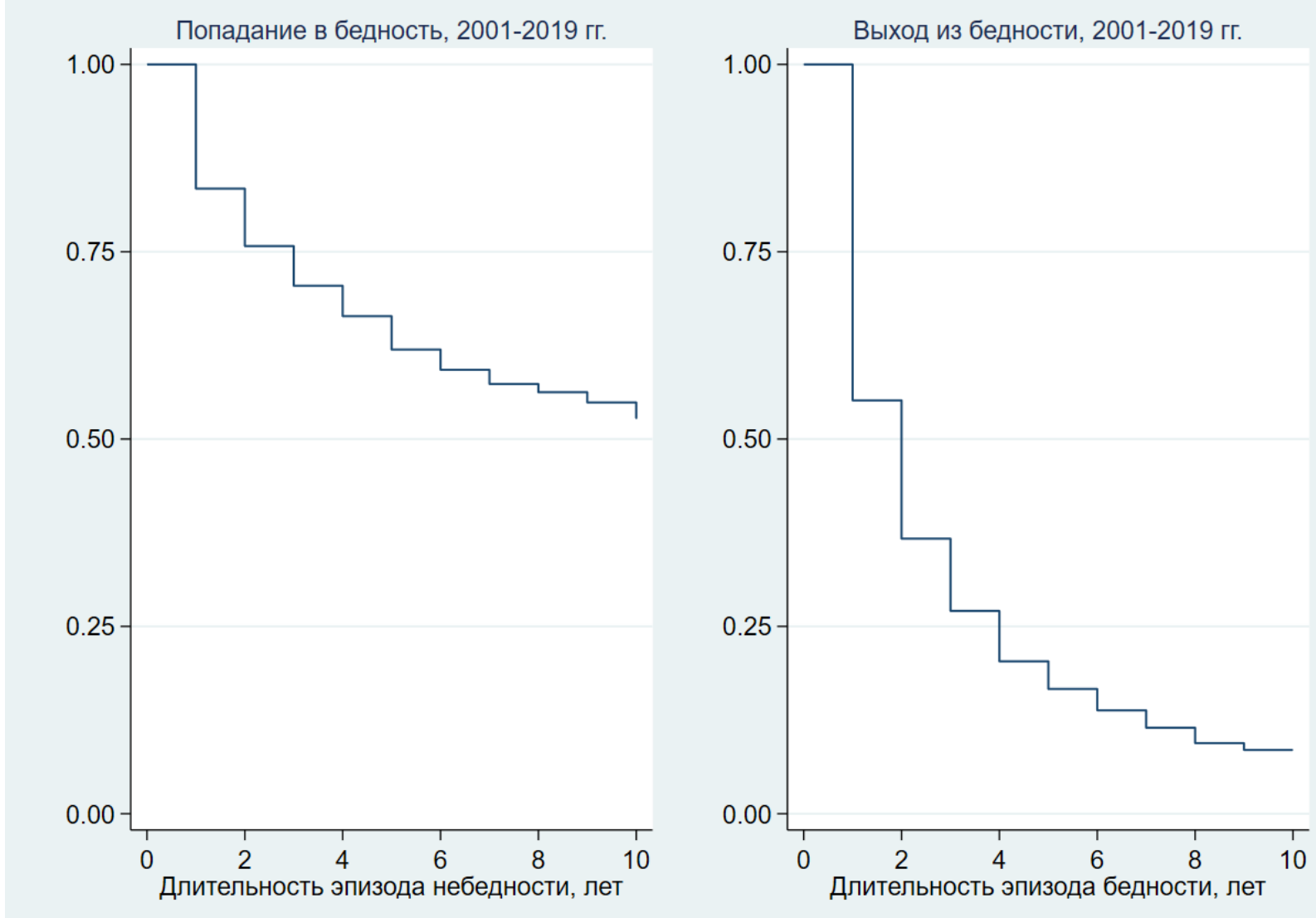

Рисунок 2. Оценка функции выживания для попадания в бедность и выхода из нее, 2001-2019

Источник: Расчеты автора по данным РМЭЗ

Для каждого из трех временных периодов (2001-2010, 2011-2019 и 2001-2019 гг.) были рассмотрены две выборки: для попадания в бедность и для выхода из нее. Чтобы учесть множественные переходы в бедность и из нее, мы разбивали ряд наблюдений за такими домохозяйствами на несколько (по числу переходов). Выборка для попадания в бедность в 2001-2019 гг. содержит 20547 домохозяйств, из которых 5848 совершали переход из небедности в бедность. Выборка для выхода из бедности содержит 11964 домохозяйств, из которых 8253 домохозяйств вышли из состояния бедности. Сведения о численности выборок 2001-2010 и 2011-2019 гг. приведены в Приложении (таблицы П1 и П2). 
Для включения в анализ информации о периодах до и после смерти члена семьи, были рассмотрены 5 временных отрезков: 1) 5-3 года до смерти члена семьи; 2) 2-1 года до смерти; 3) год смерти; 4) через 1-2 года после смерти; 5) через 3-5 лет после смерти.

Диаграммы Каплана-Мейера позволяют получить представление о зависимых переменных нашего исследования - длительности периодов бедности и небедности. На рисунке 2 представлены функции выживания для входа в бедность и выхода из нее в 2001-2019 гг. Согласно представленным данным вероятность попасть в бедность после 1го года вне бедности (рисунок 2, диаграмма слева) составляет 17\%, после 2-го года - 24\%, после 3-го - 30\%. Более половины всех домохозяйств (53\%) в выборке 2001-2019 гг. никогда не попадали в состояние бедности.
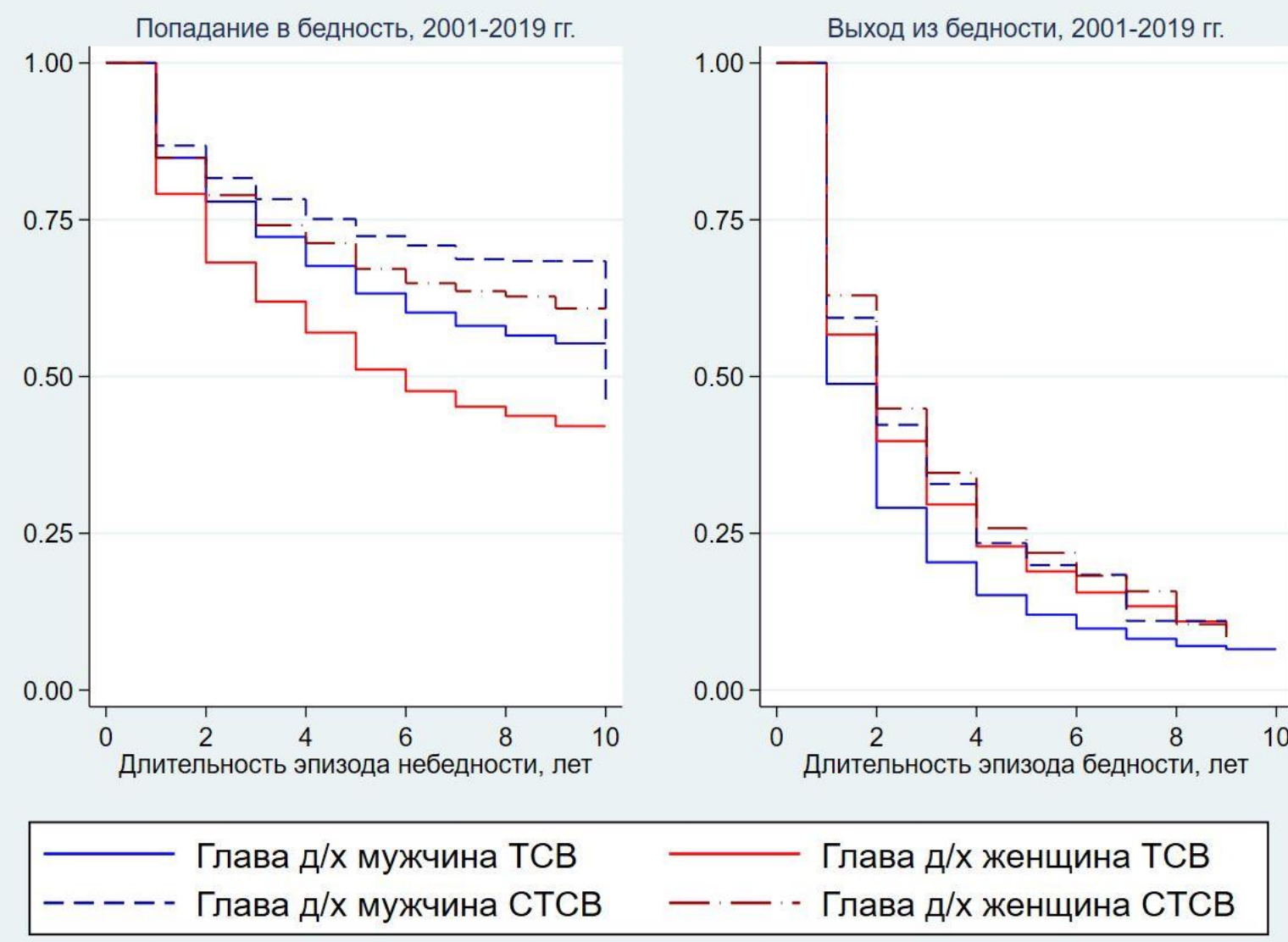

Рисунок 3. Оценка функции выживания для попадания в бедность и выхода из нее в зависимости от типа домохозяйств, 2001-2019

Источник: Расчеты автора по данным РМЭЗ.

Примечание: $\partial / x$ - домохозяйство; ТСВ - в трудоспособном возрасте; СТСВ - старие трудоспособного возраста.

Риски выхода из состояния бедности, напротив, существенно выше, о чем можно судить по быстрому убыванию кривой выживания (рисунок 2, диаграмма справа). Вероятность перестать быть бедным после 1 года пребывания в бедности составляет 45\%, после 2 лет - 63\%, после 3 - 73\%. 
На рисунках 3 и 4 представлены функции выживания в зависимости от типа домохозяйств и от того, приходилось ли им в период наблюдений переживать смерть одного из взрослых членов семьи. С наибольшими рисками попадания в бедность сталкиваются домохозяйства, возглавляемые женщинами трудоспособного возраста. Аналогичные риски домохозяйств, возглавляемых трудоспособными мужчинами, сопоставимы с вероятностью попадания в бедность для домохозяйств, в которых главой семьи являются пенсионеры. В то же время шансы выйти из бедности у домохозяйств, возглавляемых мужчинами, существенно выше, чем у остальных домохозяйств.

Домохозяйства, которые в период наблюдений пережили смерть взрослого члена семьи, демонстрируют большие риски попадания в бедность, а также с меньшей вероятностью быстро (после 1 или 2 лет бедности) выходят из нее.

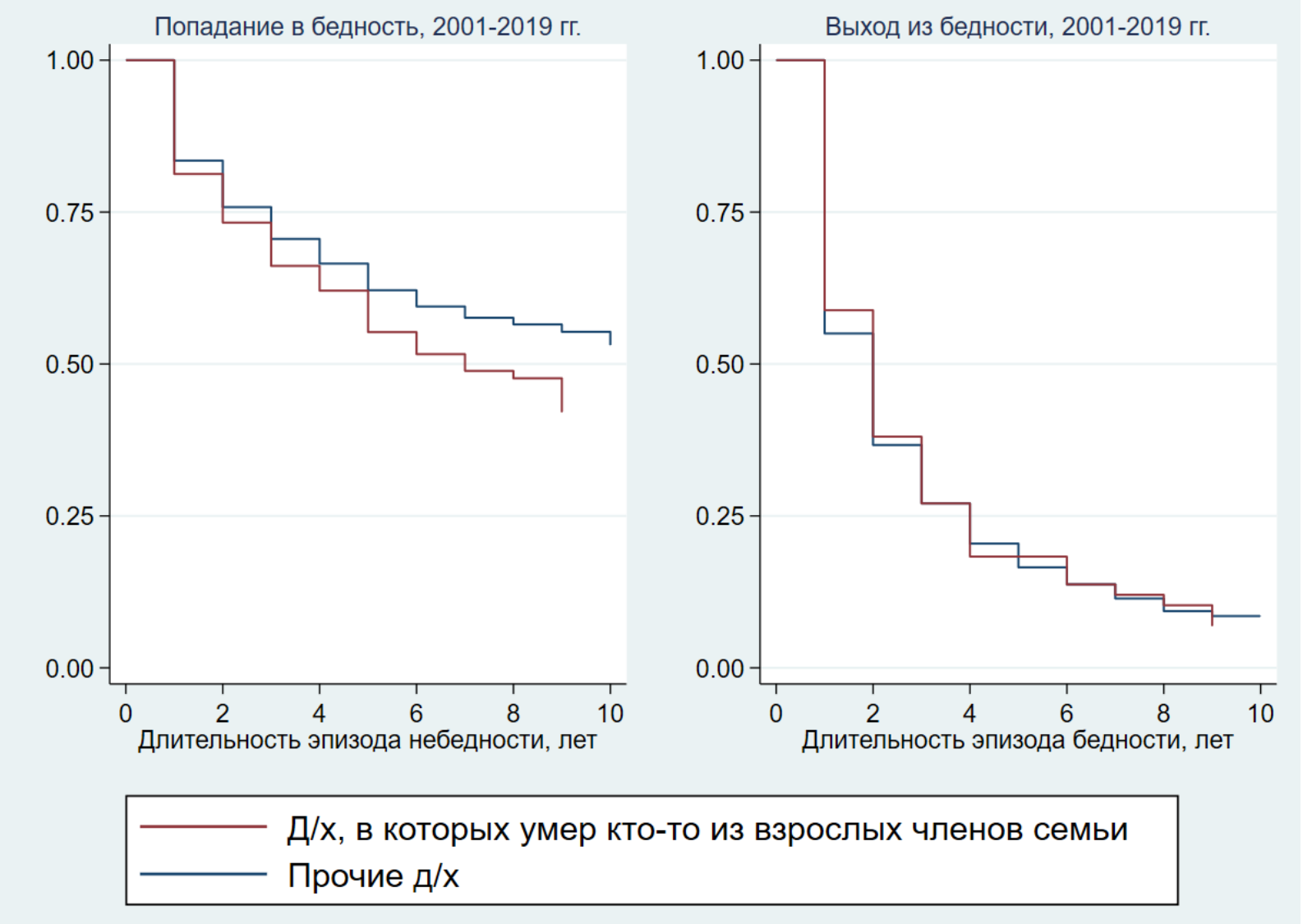

Рисунок 4. Оценка функции выживания для попадания в бедность и выхода из нее в зависимости от того, происходила ли в домохозяйстве смерть члена семьи, 2001-2019

Источник: Расчеты автора по данным РМЭЗ.

Примечание: $\partial / x-$ домохозяйство.

В таблице 2 представлены выборочные средние для переменных, включенных в регрессионный анализ. Среднее время пребывания в небедности на момент попадания в бедность для выборки 2001-2019 гг. составляет 2,75 года, что заметно больше, чем средняя длительность бедности при выходе из нее (1,83 года). 
Таблица 2. Выборочные средние переменных, включенных в регрессионный анализ, 2001-2019 гг.

\begin{tabular}{|c|c|c|}
\hline Переменная & Попадание в бедность & Выход из бедности \\
\hline Длительность пребывания в состоянии небедности, лет & 2,75 & \\
\hline Длительность пребывания в состоянии бедности, лет & & 1,83 \\
\hline Размер домохозяйства, чел. & 2,76 & 3,07 \\
\hline Число детей в возрасте до 7 лет, чел. & 0,22 & 0,28 \\
\hline Число детей в возрасте от 7 до 18 лет, чел. & 0,31 & 0,45 \\
\hline Глава семьи - женщина ТСВ & 0,28 & 0,32 \\
\hline Глава семьи - женщина СТСВ & 0,25 & 0,20 \\
\hline Глава семьи - мужчина СТСВ & 0,10 & 0,08 \\
\hline Глава семьи - мужчина ТСВ (пропущенная переменная) & 0,37 & 0,40 \\
\hline Доля работающих & 0,38 & 0,34 \\
\hline Доля безработных & 0,03 & 0,04 \\
\hline Доля имеющих высшее образование & 0,20 & 0,12 \\
\hline Доля пенсионеров & 0,44 & 0,33 \\
\hline Доля членов д/x с плохим здоровьем & 0,14 & 0,14 \\
\hline Д/х проживает в городе & 0,73 & 0,60 \\
\hline 3-5 лет до смерти мужчины 21- 60 лет & 0,002 & 0,004 \\
\hline 1-2 лет до смерти мужчины 21- 60 лет & 0,004 & 0,006 \\
\hline Год смерти мужчины 21- 60 лет & 0,006 & 0,01 \\
\hline 1-2 после смерти мужчины 21- 60 лет & 0,008 & 0,011 \\
\hline 3-5 лет после смерти мужчины 21- 60 лет & 0,007 & 0,005 \\
\hline 3-5 лет до смерти члена д/х старше ТСВ & 0,005 & 0,009 \\
\hline 1-2 лет до смерти члена д/х старше ТСВ & 0,007 & 0,013 \\
\hline Год смерти члена д/х старше ТСВ & 0,020 & 0,024 \\
\hline 1-2 года после смерти члена д/х старше ТСВ & 0,026 & 0,028 \\
\hline 3-5 лет после смерти члена д/х старше ТСВ & 0,019 & 0,015 \\
\hline Количество наблюдений & 20547 & 11964 \\
\hline Количество цензурированных наблюдений & 14699 & 3711 \\
\hline
\end{tabular}

Источник: Расчеты автора по данным РМЭЗ.

Примечание: $\partial / x$ - домохозяйство; ТСB - в трудоспособном возрасте; СТСВ - старше трудоспособного возраста.

\section{РезУЛьтаты}

\section{Влияние смерти членов семьи на благосостояние домохозяйств различного типа}

Как сказывается смерть мужчин и женщин различного возраста на благосостоянии оставшихся членов домохозяйств? В поисках ответа на этот вопрос можно взглянуть на динамику реальных доходов и бедности домохозяйства, в котором проживал умерший, в течение 5 лет до и после его смерти.

На рисунке 5 графически представлена информация о динамике уровня бедности среди домохозяйств, переживших смерть мужчины трудоспособного возраста. Реальные доходы домохозяйств в год смерти кого-то из членов семьи, независимо от пола и возраста умершего, растут. Это скорее всего объясняется низкими доходами этого человека незадолго до смерти, в связи с чем в год смерти из-за снижения размера семьи ее доход в подушевом исчислении растет. Также следует отметить низкую численность ряда интересующих нас событий, прежде всего смертей женщин трудоспособного возраста. 
В целом с 2001 по 2019 г. в выборке присутствует 192 таких случая, не более 15 случаев в год.

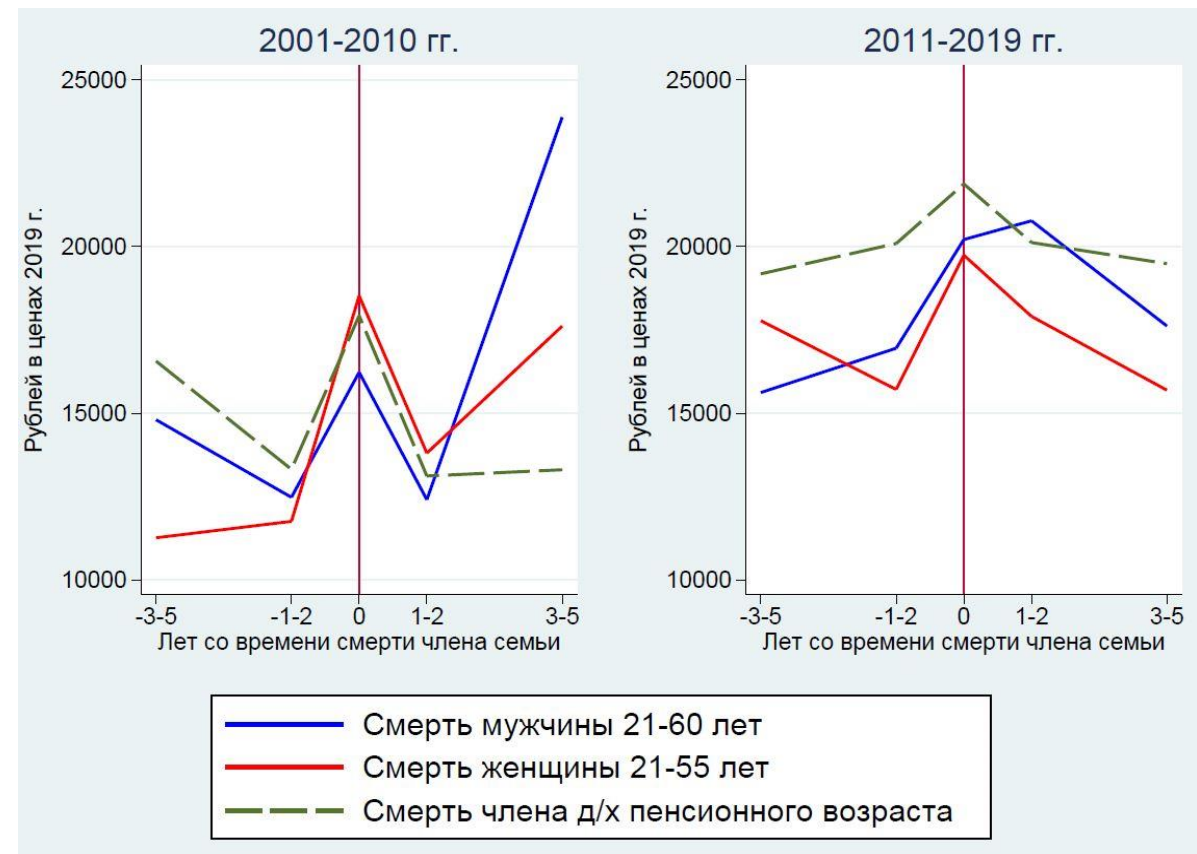

Рисунок 5. Динамика средних реальных подушевых доходов домохозяйств, переживших смерть одного из членов семьи, 2001-2019

Источник: Расчеты автора по данным РМЭЗ.

Примечание: $\partial / x-$ домохозяйство.
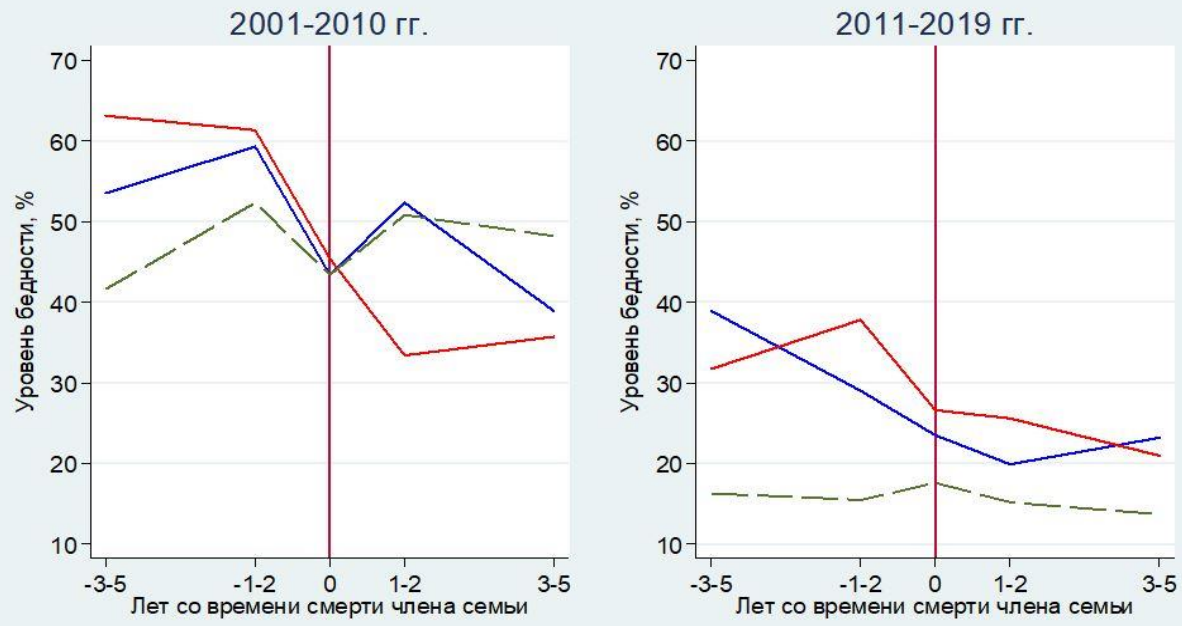

Смерть мужчины 21-60 лет

Смерть женщины 21-55 лет

Смерть члена $\mathrm{g} / \mathrm{x}$ пенсионного возраста

Рисунок 6. Динамика бедности среди домохозяйств, переживших смерть одного из членов семьи, 2001-2019

Источник: Расчеты автора по данным РМЭЗ.

Примечание: $\partial / x-$ домохозяйство. 
Взаимосвязь между смертью членов семьи и бедностью домохозяйств, в которых они проживали, графически представлена на рисунке 6. В 2010-х годах уровень бедности домохозяйств, потерявших кого-то из членов семьи, существенно ниже, чем в предыдущее десятилетие, но это не меняет характера влияния смерти на бедность. Эффект снижения бедности непосредственно в год смерти члена семьи наблюдается почти во всех случаях, независимо от периода наблюдений, а также пола и возраста умершего. Исключение составляет лишь семьи, где умер пенсионер, в 2011-2019 гг. для них зафиксирован небольшой рост бедности.

Как мы видим, динамика среднедушевых доходов и бедности в домохозяйствах, переживших смерть кого-то из членов семьи, свидетельствует, что эффект от снижения размера семьи преобладает над эффектом от снижения доходов. Скорее всего это происходит из-за того, что благосостояние домохозяйств ухудшается не в год смерти человека, а раньше. О том, насколько справедливым является это предположение, можно судить по результатам анализа факторов бедности или доходов с учетом гетерогенности индивидуумов и домохозяйств, включенных в выборку. Это было сделано с помощью регрессионного анализа.

\section{РЕГРЕССИОННЫЙ АНАЛИЗ ВЛИЯНИЯ СМЕРТИ ЧЛЕНОВ СЕМЬИ НА БЕДНОСТЬ ДОМОХОЗЯЙСТВ}

В регрессионной модели длительности мы оцениваем риски изучаемого события, т. е. попадания в бедность или выхода из нее в зависимости от продолжительности эпизода небедности (бедности), предшествовавшего такому переходу. Для этого рассматриваем наблюдения с завершенными эпизодами, т. е. те случаи, когда состояние небедности в какой-то момент завершилось переходом в бедность. Для них риск попадания в бедность оцениваем как условную вероятность того, что период выживания закончится в момент $\mathrm{t}$ при условии, что он не закончился раньше. Одновременно с этим оцениваем функции выживания для незавершенных эпизодов. При расчетах была использована полупараметрическая модель Кокса - модель пропорциональных рисков, где функция риска представляет собой произведение базовой функции риска и отношения рисков, которое смещает базовый риск в зависимости от характеристик наблюдаемого домохозяйства. Результаты оценки факторов попадания в бедность представлены графически (рисунок 7) и в табличном виде (таблица П1 Приложения). Результаты представлены коэффициентом регрессии (логарифм отношения шансов), вследствие чего они могут быть как положительными, так и отрицательными. Значимыми являются факторы, для которых коэффициент регрессии лежит по одну сторону от красной линии нуля. Были оценены регрессионные модели для 3 временных периодов: полная выборка 2001-2019, а также подвыборки 2001-2010 и 2011-2019 гг.

На рисунке 7 результаты анализа выживаемости для риска попадания в бедность представлены графически. Точки соответствуют значениям логарифма отношения рисков, а проходящие через них отрезки - 90\%-ным доверительным интервалам. Для факторов, значимо способствующих росту риска попадания домохозяйства в состояние бедности, 
значения коэффициентов положительны (находятся в правой части каждого из графиков рисунка 7), а доверительный интервал не пересекает линию нуля.

Согласно проведенным расчетам, демографические характеристики домохозяйства оказывают существенное влияние на риски попадания в бедность. Так, с ростом размера домохозяйства вероятность стать бедным для подвыборки 2011-2019 гг. значимо увеличивается. Присутствие в домохозяйстве несовершеннолетних детей также повышает вероятность попадания в состояние бедности.

Домохозяйства, во главе которых стоят женщины как трудоспособного, так и пенсионного возраста, имеют существенно более высокие риски бедности по сравнению с референтной категорией (мужчины трудоспособного возраста). Однако риски бедности для женщин пенсионного возраста смягчаются влиянием переменной «доля лиц пенсионного возраста в составе семьи», и суммарный эффект от того, что домохозяйство возглавляет женщина пенсионного возраста, способствует снижению вероятности попадания в бедность.

Ожидаемо важным фактором бедности является статус членов домохозяйства на рынке труда: риск бедности растет с увеличением доли безработных и снижением доли работающих членов семьи. Наличие высшего образования у членов семьи снижает вероятность попадания в бедность. Заметного влияния на риск попадания в бедность фактора плохого здоровья членов семьи выявлено не было. Проживание в городской местности способствует снижению риска попадания в бедность.

Наибольший интерес в рамках данного исследования представляют переменные, связанные со смертью респондентов. В связи с малым количеством смертей женщин трудоспособного возраста в выборке РМЭЗ информацию о таких смертях в модель не включали. При добавлении в модель сведений о годе смерти кого-то из членов домохозяйств практически ничего не меняется: значимо способствует росту бедности лишь смерть членов семьи пенсионного возраста из-за потери домохозяйством гарантированного дохода - пенсии умершего. Коэффициенты для года смерти мужчин трудоспособного возраста оказались незначимы для всех вариантов модели.

Можно предположить, что риски попадания в бедность растут не в момент смерти еще не старого человека, а раньше, в момент, когда у него появляются существенные проблемы со здоровьем. Включение в модель переменных для периодов до и после смерти членов домохозяйств (3-5 лет и 1-2 года до и после смерти) позволяет проверить эту гипотезу. На рисунке 7 хорошо видно влияние смерти мужчин трудоспособного возраста на бедность: повышенные риски попадания в бедность за 1-5 лет до смерти и спустя 1-5 лет после нее. Для семей, в которых умер член семьи пенсионного возраста, риски попадания в бедность также наиболее высоки за 3-5 лет и 1-2 года до события смерти.

Также можно предположить, что риски попадания в бедность после смерти мужчин трудоспособного возраста несколько занижены из-за того, что в таких домохозяйствах с высокой вероятностью меняется его тип - с домохозяйства, возглавляемого мужчиной трудоспособного возраста, на домохозяйство, возглавляемое женщиной. 


\section{Попадание в бедность}

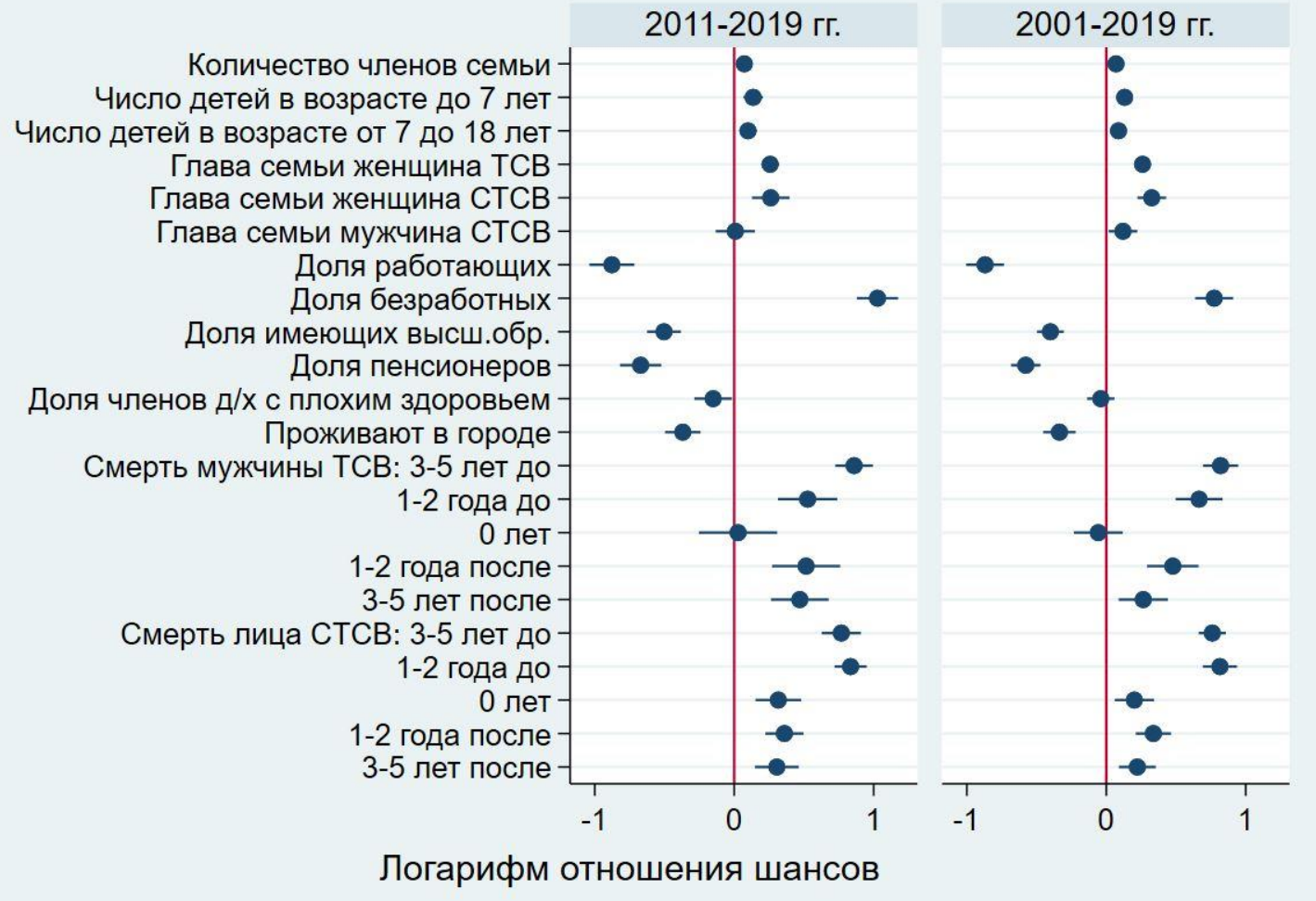

Рисунок 7. Результаты анализа длительности пребывания в небедности, 2011-2019 и 2001-2019

Источник: Расчеты автора по данньмм РМЭЗ.

Примечание: $\partial / x$ - домохозяйство; ТСВ - в трудоспособном возрасте; СТСВ - старше трудоспособного возраста.

При анализе процесса выхода из состояния бедности изучали тот же набор факторов, что и при анализе попадания домохозяйств в число бедных, однако выявленные взаимосвязи не всегда являются зеркальным отображением более ранних результатов. Результаты модели пропорциональных рисков применительно к выходу домохозяйств из состояния бедности представлены в таблице П2 Приложения и на рисунке 8.

Влияние факторов состава семьи является предсказуемым: риски выхода из бедности значимо снижаются для семей с большим присутствием несовершеннолетних детей, безработных и лиц с низкой самооценкой здоровья и, напротив, растут, если в семье больше работающих, пенсионеров и членов семьи с высшим образованием. Домохозяйства, возглавляемые мужчинами трудоспособного возраста, имеют более высокие шансы выхода из бедности по сравнению со всеми другими типами домохозяйств. Следует также отметить, что абсолютное значение влияния перечисленных факторов на риски выхода из бедности в целом заметно ниже, чем для рисков попадания в бедность.

Интересный и отчасти неожиданный эффект смерти взрослого члена семьи наблюдается за 3-5 лет и 1-2 года до события его смерти. Вероятность выйти из состояния бедности в этот момент растет, причем этот эффект наблюдается в случае смерти как пенсионеров, так и мужчин трудоспособного возраста. Возможно, это объясняется ростом 
доходов в связи с оформлением инвалидности, хотя влияние переменной «доля членов домохозяйства с плохим здоровьем» для всех трех выборок оказалось незначительным (существуют эмпирические подтверждения того, что самооценка здоровья существенно коррелирует с объективными показателями состояния здоровья, к числу которых относится и наличие инвалидности (Wu et al. 2013)).

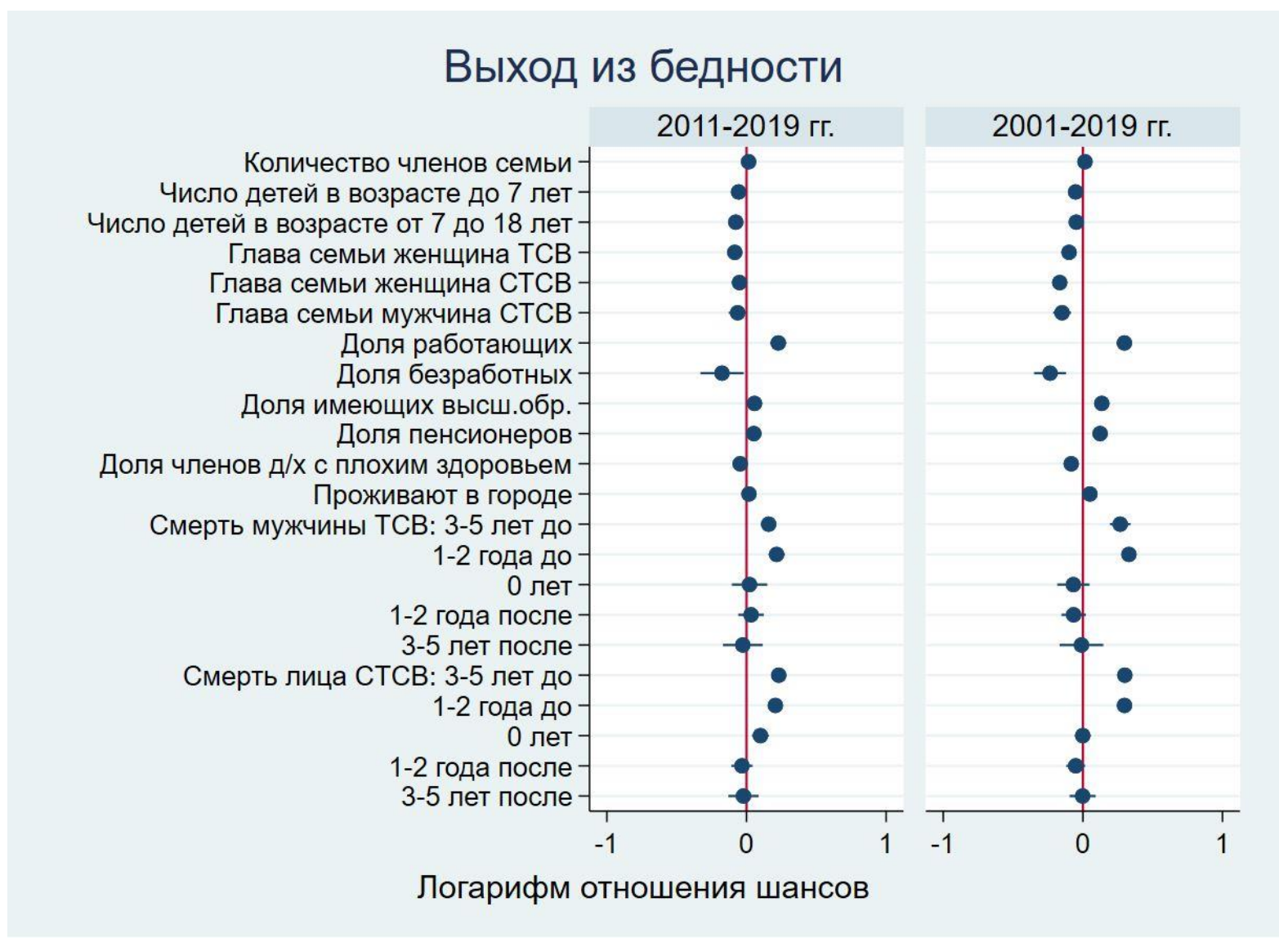

Рисунок 8. Результаты анализа длительности пребывания в бедности, 2011-2019 и 2001-2019

Источник: Расчеты автора по данным РМЭЗ.

Примечание: д/x-домохозяйство; ТСВ - в трудоспособном возрасте; СТСВ - старше трудоспособного возраста.

\section{ЗАКЛЮЧЕНИЕ}

Эмпирический анализ взаимосвязи смертности и благосостояния требует использования данных панельного репрезентативного социологического обследования. В России существует единственный источник данных подобного рода - Российский мониторинг экономического положения и здоровья населения НИУ ВШЭ (РМЭЗ). В ходе исследования было показано, что ошибка оценки смертности с помощью данных РМЭЗ носит систематический характер и в основном сконцентрирована в определенных (старших) возрастных группах. 
Регрессионный анализ длительности, примененный к данным РМЭ3 2001-2019 гг., позволил выявить факторы, оказывающие влияние на вероятность попадания домохозяйств в бедность и выхода из нее. Согласно проведенным расчетам риски попадания в бедность ниже, если в домохозяйстве есть работающие, пенсионеры, а также лица с высшим образованием. Риски попадания в бедность выше, если в домохозяйстве есть безработные, несовершеннолетние дети или если глава домохозяйства - женщина. Абсолютный эффект от воздействия факторов на выход из бедности оказался заметно меньше, чем для рисков попадания в нее.

Отдельно изучили влияние на бедность и доходы домохозяйств смерти членов семьи в зависимости от их пола и возраста (мужчин трудоспособного возраста, а также лиц старше трудоспособного возраста). Было показано, что смерть мужчин трудоспособного возраста значимо влияет на бедность: наблюдаются повышенные риски попадания в бедность за 1-5 лет до смерти и спустя 1-5 года после нее.

Таким образом, удалось доказать, что смерть мужчин трудоспособного возраста негативно сказывается на благосостоянии домохозяйств. Вообще говоря, этот вывод не является очевидным. Было показано, что в год смерти члена семьи трудоспособного возраста душевые доходы остальных членов домохозяйства растут, а риски бедности снижаются, т. е. эффект от снижения размера домохозяйства преобладает над эффектом от сокращения его доходов. Тем не менее изучение благосостояния домохозяйств не только в год смерти члена семьи, но и в течение 5 лет до и после этого события позволяет увидеть заметный рост риска попадания в бедность для домохозяйств, в которых умирает мужчина трудоспособного возраста.

Результаты, полученные в ходе исследования, могут быть использованы при разработке мероприятий социальной политики. Было показано, что снижение размера домохозяйства в год смерти члена семьи не позволяет увидеть ухудшение финансового положения оставшегося домохозяйства, однако и накануне смерти, и в течение нескольких лет спустя такие семьи сталкиваются с повышенными рисками попадания в бедность. Предупредить бедность семей, столкнувшихся с потерей близких или их тяжелой болезнью, могут меры социальной поддержки, реализуемые как в материальной, так и нематериальной форме (психологическая помощь, предоставление услуг долговременного ухода, помощь в трудоустройстве и др.).

\section{БЛАГОДАРНОСТИ}

Автор выражает благодарность двум анонимным рецензентам за внимательное знакомство с текстом и ценные замечания.

\section{ЛИТЕРАТУРА}

Абанокова К.Р. (2015). Изменения в структуре российских домохозяйств в 19942013 гг. (статистический анализ). Демографическое обозрение, 2(1), 125-147. DOI: https://doi.org/10.17323/demreview.v2i1.1791 
Андреев Е.М. Смертность мужчин в России. (2001). Вопросы статистики, 7, 27-33.

Аникин В. А., Тихонова Н. Е. (2014). Бедность в России на фоне других стран. Мир России. Сочиология. Этнология, 23(4).

Гришина Е.Е. (2018). Различные аспекты бедности семей с детьми. Всероссийский экономический журнал ЭКО, 525(3), 7-26.

Захаров С.В., Чурилова Е.В. (2013). Феномен одинокого материнства в России: статистико-демографический анализ распространенности и механизмов его формирования. Мир России. Социиология. Этнология, 22(4), 86-117.

Ратникова Т. А., Фурманов К. К. (2014). Анализ панельных данных и данных о длительности состояний: учебное пособие. М.: Изд. Дом ВШЭ.

Чернышева И. К., Фурманов К. К. (2013). Российский мониторинг экономического положения и здоровья населения как источник данных о смертности: возможности и ограничения. Демоскоп Weekly, № 567-568.

Adams P., Hurd M. D., McFadden D., Merrill A., Ribeiro T. (2003). Healthy, wealthy, and wise? Tests for direct causal paths between health and socioeconomic status. Journal of econometrics, 112(1), 3-56.

Ahammer A., Horvath T. A., Winter-Ebmer R. (2015). The effect of income on mortality: new evidence for the absence of a causal link. IZA Discussion Paper, 9176.

Bane M. J., Ellwood D. T. (1986). Slipping into and out of Poverty: the Dynamics of Spells. Journal of Human Resources, 20(1), 1-23.

Becker G.S. (2009a). Human capital: A theoretical and empirical analysis, with special reference to education. University of Chicago press.

Becker G. S. (2009b). A Treatise on the Family. Harvard university press.

Cappellari L., Jenkins S. P. (2002). Who stays poor? Who becomes poor? Evidence from the British household panel survey. The Economic Journal, 112(478), 60-C67. https://doi.org/10.1111/1468-0297.00028

Cox D.R. (1972). Regression models and life-tables. Journal of the Royal Statistical Society: Series B (Methodological), 34(2), 187-202.

Evans W. N., Moore T. J. (2011). The short-term mortality consequences of income receipt. Journal of Public Economics, 95 (11-12), 1410-1424

Denisova I. (2007). Entry to and exit from poverty in Russia: Evidence from longitudinal data. Working Papers w0098, New Economic School (NES).

Denisova I. (2010). Adult mortality in Russia. Economics of Transition, 18(2), 333-363.

Duleep H.O. (1986). Measuring the effect of income on adult mortality using longitudinal administrative record data. Journal of Human Resources, 238-251.

Evans W. N., Moore T. J. (2011). The short-term mortality consequences of income receipt. Journal of Public Economics, 95 (11-12), 1410-1424

Fusco A., Islam N. (2012). Chapter 14 Understanding the Drivers of Low-Income Transitions in Luxembourg. In J.A. Bishop, J.A., R.Salas (Eds.) Inequality, Mobility and Segregation: Essays in Honor of Jacques Silber (Research on Economic Inequality, Vol. 20) (pp. 367391). Emerald Group Publishing Limited, Bingley. DOI: https://doi.org/10.1108/S10492585(2012)0000020017 
Grigoriev P., Jasilionis D., Klüsener S., Timonin S., Andreev E., Meslé F., Vallin J. (2020). Spatial patterns of male alcohol-related mortality in Belarus, Lithuania, Poland and Russia. Drug and alcohol review, 39(7), 835-845.

Grossman M. The demand for health: a theoretical and empirical investigation. Columbia University Press, 1972.

Haq R., Arif G.M. (2004). Transition of Poverty in Pakistan: Evidence from the Longitudinal Data. The Pakistan Development Review, Pakistan Institute of Development Economics, 43(4), 895-909.

Jenkins S.P., Van Kerm P. (2014). The relationship between EU indicators of persistent and current poverty. Social indicators research, 116(2), 611-638. DOI: https://doi.org/10.1007/s11205-013-0282-2

Jusot F. (2006). The shape of the relationship between mortality and income in France. Annales d'Economie et de Statistique, 89-122.

Klein J. P., Moeschberger M. L. (2003). Survival analysis: techniques for censored and truncated data (Vol. 1230). New York: Springer.

Kossova T., Kossova E., Sheluntcova M. (2020). Gender gap in life expectancy in Russia: The role of alcohol consumption. Social Policy and Society, 19(1), 37-53.

Leopold T. (2018). Gender differences in the consequences of divorce: A study of multiple outcomes. Demography, 55(3), 769-797. https://doi.org/10.1007/s13524-018-0667-6

Lindquist M.J., Lindquist G.S. (2012). The dynamics of child poverty in Sweden. Journal of Population Economics, 25(4), 1423-1450.

Mather D. (2011). Working-age Adult Mortality, Orphan Status, and Child Schooling in Rural Mozambique. Food Security International Development Working Papers 119320, Michigan State University, Department of Agricultural, Food, and Resource Economics.

McKernan S.M., Ratcliffe C. (2005). Events that trigger poverty entries and exits. Social Science Quarterly, 86, 1146-1169. DOI: https://doi.org/10.1111/j.0038-4941.2005.00340.x

Mehta N.K., House J.S., Elliott M.R. (2015). Dynamics of health behaviours and socioeconomic differences in mortality in the USA. J Epidemiol Community Health, 69(5), 416-422. DOI: https://dx.doi.org/10.1136\%2Fjech-2014-204248

Mincer J. (1993). Studies in human capital (Vol. 1). Edward Elgar Publishing.

Munnell A. H., Eschtruth A. D. (2018). Modernizing Social Security: Widow benefits. Center for Retirement Research at Boston College, Issue in Brief, No. 18-17, Chestnut Hill, Mass.: September 2018. http://hdl.handle.net/2345/bc-ir:108142

Munnell A. H., Sanzenbacher G., Zulkarnain A. (2019). Why has poverty declined for widows? Center for Retirement Research at Boston College, Issue in Brief, No. 19-4, Chestnut Hill, Mass.: February 2019. http://hdl.handle.net/2345/bc-ir:108360

Ozdamar O., Giovanis E. (2017). The causal effects of survivors' benefits on health status and poverty of widows in Turkey: Evidence from Bayesian Networks. Economic Analysis and Policy, 53, 46-61. DOI: https://doi.org/10.1016/j.eap.2016.11.001

Perlman F., Bobak M. (2008). Determinants of self rated health and mortality in Russia-are they the same? International Journal for Equity in Health, 7(1), 19. DOI:

https://doi.org/10.1186/1475-9276-7-19 
Shkolnikov V.M., Andreev E.M., McKee M., Leon D.A. (2013). Components and possible determinants of the decrease in Russian mortality in 2004-2010. Demographic research, 28, 917-950. DOI: https://dx.doi.org/10.4054/DemRes.2013.28.32

Snyder S. E., Evans W. N. (2006). The effect of income on mortality: evidence from the Social Security notch. Review of Economics and Statistics, 88 (3), 482-495.

Sydén L., Landberg J. (2017). The contribution of alcohol use and other lifestyle factors to socioeconomic differences in all-cause mortality in a Swedish cohort. Drug and alcohol review, 36(5), 691-700. DOI: https://doi.org/10.1111/dar.12472

Yamauchi F., Buthelezi T., Velia M. (2006). Gender, labor, and prime-age adult mortality: Evidence from South Africa. №. 583-2016-39554.

Wu S., Wang R., Zhao Y., Ma X., Wu M., Yan X., He J. (2013). The relationship between self rated health and objective health status: A population-based study. BMC public health, 13(1), 1-9. DOI: https://doi.org/10.1186/1471-2458-13-320 


\title{
PREMATURE MALE MORTALITY
}

\section{AND THE ECONOMIC WELL-BEING OF HOUSEHOLDS}

\author{
POLINA KUZNETSOVA
}

\begin{abstract}
The paper examines the impact of the death of family members, including men of working age, on the economic wellbeing of their households. It is shown that the data from the Russian Monitoring of Economic Condition and Health (RLMS) can, despite a certain systematic error in registering the deaths of respondents, be used to assess the mortality rate of men and people of working age.

The RLMS data showed that in the year when a family member dies, the average real per capita household income grows. That is, the effect of a decrease in family size turns out to be stronger than the effect of a drop in total income. The fact is that the economic problems of the household associated with the loss of family members do not begin in the year of death, but much earlier. Therefore, a wider time range was considered, from five years before the death of a family member to five years after it. Regression analysis of the processes of falling into and out of poverty showed that the death of family members has a negative impact on the wellbeing of other members of the household. If a man of working age dies, the risks of falling into poverty increase for 1-5 years before and 1-5 years after this event.
\end{abstract}

Key words: mortality, panel data, poverty, survival analysis, household structure, RLMS.

\footnotetext{
Polina KuZnetsova (polina.kuznetsova29@gmail.com), Russian PrESIDENTIAL ACADEMY Of NATIONAL ECONOMY AND PUBLIC ADMINISTRATION, RUSSIA.
}

THIS ARTICLE WAS PREPARED AS PART OF THE RESEARCH WORK OF THE STATE ASSIGNMENT OF THE RANEPA.

DATE RECEIVED : JUNE 2021.

\section{REFERENCES}

Adams P., Hurd M. D., McFadden D., Merrill A., Ribeiro T. (2003). Healthy, wealthy, and wise? Tests for direct causal paths between health and socioeconomic status. Journal of econometrics, 112(1), 3-56.

Abanokova K.R. (2015). Changes in the structure of Russian households in 1994-2013 (statistical analysis). Demographic Review, 2(1), 125-147. (In Russ.) DOI: https://doi.org/10.17323/demreview.v2i1.1791

Ahammer A., Horvath T. A., Winter-Ebmer R. (2015). The effect of income on mortality: new evidence for the absence of a causal link. IZA Discussion Paper, 9176.

Andreev E.M. Mortality of men in Russia. (2001). Voprosy statistiki, 7, 27-33. (In Russ.)

Anikin V., Tikhonova N. (2014). Framing Contemporary Russian Poverty in the Context of Different Nations. Universe of Russia, 23(4), 59-94. (In Russ.)

Bane M. J., Ellwood D. T. (1986). Slipping into and out of Poverty: the Dynamics of Spells. Journal of Human Resources, 20(1), 1-23.

Becker G.S. (2009a). Human capital: A theoretical and empirical analysis, with special reference to education. University of Chicago press.

Becker G. S. (2009b). A Treatise on the Family. Harvard university press. 
Cappellari L., Jenkins S. P. (2002). Who stays poor? Who becomes poor? Evidence from the British household panel survey. The Economic Journal, 112(478), 60-C67. https://doi.org/10.1111/1468-0297.00028

Chernysheva I.K., Furmanov K.K. (2013). Russian monitoring of the economic situation and health of the population as a source of data on mortality: opportunities and limitations. Demoscope Weekly, № 567-568. (In Russ.).

Cox D.R. (1972). Regression models and life-tables. Journal of the Royal Statistical Society: Series B (Methodological), 34(2), 187-202.

Evans W. N., Moore T. J. (2011). The short-term mortality consequences of income receipt. Journal of Public Economics, 95 (11-12), 1410-1424

Denisova I. (2007). Entry to and exit from poverty in Russia: Evidence from longitudinal data. Working Papers w0098, New Economic School (NES).

Denisova I. (2010). Adult mortality in Russia. Economics of Transition, 18(2), 333-363.

Duleep H.O. (1986). Measuring the effect of income on adult mortality using longitudinal administrative record data. Journal of Human Resources, 238-251.

Evans W. N., Moore T. J. (2011). The short-term mortality consequences of income receipt. Journal of Public Economics, 95 (11-12), 1410-1424

Fusco A., Islam N. (2012). Chapter 14 Understanding the Drivers of Low-Income Transitions in Luxembourg. In J.A. Bishop, J.A., R.Salas (Eds.) Inequality, Mobility and Segregation: Essays in Honor of Jacques Silber (Research on Economic Inequality, Vol. 20) (pp. 367391). Emerald Group Publishing Limited, Bingley. DOI: https://doi.org/10.1108/S10492585(2012)0000020017.

Grigoriev P., Jasilionis D., Klüsener S., Timonin S., Andreev E., Meslé F., Vallin J. (2020). Spatial patterns of male alcohol-related mortality in Belarus, Lithuania, Poland and Russia. Drug and alcohol review, 39(7), 835-845.

Grishina E.E. (2018). Different Aspects of Poverty among Families with children. ECO Journal, 525(3), 7-26. (In Russ.)

Grossman M. The demand for health: a theoretical and empirical investigation. Columbia University Press, 1972.

Haq R., Arif G.M. (2004). Transition of Poverty in Pakistan: Evidence from the Longitudinal Data. The Pakistan Development Review, Pakistan Institute of Development Economics, 43(4), 895-909.

Jenkins S.P., Van Kerm P. (2014). The relationship between EU indicators of persistent and current poverty. Social indicators research, 116(2), 611-638. DOI: https://doi.org/10.1007/s11205-013-0282-2

Jusot F. (2006). The shape of the relationship between mortality and income in France. Annales d'Economie et de Statistique, 89-122.

Klein J. P., Moeschberger M. L. (2003). Survival analysis: techniques for censored and truncated data (Vol. 1230). New York: Springer.

Kossova T., Kossova E., Sheluntcova M. (2020). Gender gap in life expectancy in Russia: The role of alcohol consumption. Social Policy and Society, 19(1), 37-53.

Leopold T. (2018). Gender differences in the consequences of divorce: A study of multiple outcomes. Demography, 55(3), 769-797. https://doi.org/10.1007/s13524-018-0667-6 
Lindquist M.J., Lindquist G.S. (2012). The dynamics of child poverty in Sweden. Journal of Population Economics, 25(4), 1423-1450.

Mather D. (2011). Working-age Adult Mortality, Orphan Status, and Child Schooling in Rural Mozambique. Food Security International Development Working Papers 119320, Michigan State University, Department of Agricultural, Food, and Resource Economics.

McKernan S.M., Ratcliffe C. (2005). Events that trigger poverty entries and exits. Social Science Quarterly, 86, 1146-1169. DOI: https://doi.org/10.1111/j.0038-4941.2005.00340.x

Mehta N.K., House J.S., Elliott M.R. (2015). Dynamics of health behaviours and socioeconomic differences in mortality in the USA. J Epidemiol Community Health, 69(5), 416-422. DOI: https://dx.doi.org/10.1136\%2Fjech-2014-204248

Mincer J. (1993). Studies in human capital (Vol. 1). Edward Elgar Publishing.

Munnell A. H., Eschtruth A. D. (2018). Modernizing Social Security: Widow benefits. Center for Retirement Research at Boston College, Issue in Brief, No. 18-17, Chestnut Hill, Mass.: September 2018. http://hdl.handle.net/2345/bc-ir:108142

Munnell A. H., Sanzenbacher G., Zulkarnain A. (2019). Why has poverty declined for widows? Center for Retirement Research at Boston College, Issue in Brief, No. 19-4, Chestnut Hill, Mass.: February 2019. http://hdl.handle.net/2345/bc-ir:108360

Ozdamar O., Giovanis E. (2017). The causal effects of survivors' benefits on health status and poverty of widows in Turkey: Evidence from Bayesian Networks. Economic Analysis and Policy, 53, 46-61. DOI: https://doi.org/10.1016/j.eap.2016.11.001

Perlman F., Bobak M. (2008). Determinants of self rated health and mortality in Russia-are they the same? International Journal for Equity in Health, 7(1), 19. DOI: https://doi.org/10.1186/1475-9276-7-19

Ratnikova T., Furmanov K. (2014). Panel data and duration analysis. Moscow: HSE. (In Russ.)

Shkolnikov V.M., Andreev E.M., McKee M., Leon D.A. (2013). Components and possible determinants of the decrease in Russian mortality in 2004-2010. Demographic research, 28, 917-950. DOI: https://dx.doi.org/10.4054/DemRes.2013.28.32

Snyder S. E., Evans W. N. (2006). The effect of income on mortality: evidence from the Social Security notch. Review of Economics and Statistics, 88 (3), 482-495.

Sydén L., Landberg J. (2017). The contribution of alcohol use and other lifestyle factors to socioeconomic differences in all-cause mortality in a Swedish cohort. Drug and alcohol review, 36(5), 691-700. DOI: https://doi.org/10.1111/dar.12472

Yamauchi F., Buthelezi T., Velia M. (2006). Gender, labor, and prime-age adult mortality: evidence from South Africa. FCND discussion papers 208, International Food Policy Research Institute (IFPRI).

Wu S., Wang R., Zhao Y., Ma X., Wu M., Yan X., He J. (2013). The relationship between self rated health and objective health status: A population-based study. BMC public health, 13(1), 1-9. DOI: https://doi.org/10.1186/1471-2458-13-320

Zakharov S.V., Churilova E.V. (2013). Single Motherhood in Russia: Statistical and Demographic Analysis of its Prevalence and Formation Patterns. Universe of Russia. Sociology. Ethnology, 22(4), 86-117. (In Russ.) 


\section{ПРИЛОЖЕНИЕ}

\section{Таблица П1. Факторы попадания домохозяйств в бедность} (полупараметрическая регрессия Кокса)

\begin{tabular}{|c|c|c|c|}
\hline & $\begin{array}{c}\text { Модель } 1 \\
(2001-2010 \text { гг.) }\end{array}$ & $\begin{array}{c}\text { Модель } 2 \\
(2011-2019 \text { гг.) }\end{array}$ & $\begin{array}{r}\text { Модель } 3 \\
(2001-2019\end{array}$ \\
\hline \multirow{2}{*}{ Размер домохозяйства } & $0,078 * * *$ & $0,072 * * *$ & $0,070^{* * *}$ \\
\hline & {$[0,019]$} & {$[0,015]$} & {$[0,013]$} \\
\hline \multirow{2}{*}{ Число детей в возрасте до 7 лет } & 0,058 & $0,136^{* * *}$ & $0,132 * * *$ \\
\hline & {$[0,040]$} & {$[0,042]$} & {$[0,035]$} \\
\hline \multirow{2}{*}{ Число детей в возрасте от 7 до 18 лет } & 0,029 & $0,099 * * *$ & $0,088^{* * *}$ \\
\hline & {$[0,031]$} & {$[0,038]$} & {$[0,030]$} \\
\hline \multicolumn{4}{|c|}{ Пол и возраст главы семьи (пропущенная переменная: глава семьи -мужчина ТСВ) } \\
\hline \multirow{2}{*}{ Глава семьи - женщина ТСВ } & $0,284 * * *$ & $0,258 * * *$ & $0,260 * * *$ \\
\hline & {$[0,051]$} & {$[0,039]$} & {$[0,033]$} \\
\hline \multirow{2}{*}{ Глава семьи - женщина СТСВ } & $0,241 * * *$ & $0,262 * * *$ & $0,326^{* * *}$ \\
\hline & {$[0,062]$} & {$[0,082]$} & {$[0,063]$} \\
\hline \multirow{2}{*}{ Глава семьи - мужчина СТСВ } & $0,324 * * *$ & 0,008 & $0,120^{*}$ \\
\hline & {$[0,075]$} & {$[0,086]$} & {$[0,064]$} \\
\hline \multirow{2}{*}{ Доля работающих } & $-0,903$ & $-0,878 * * *$ & $-0,869 * * *$ \\
\hline & {$[0,093]$} & {$[0,098]$} & {$[0,083]$} \\
\hline \multirow{2}{*}{ Доля безработных } & $0,473 * * *$ & $1,027 * * *$ & $0,774 * * *$ \\
\hline & {$[0,015]$} & {$[0,090]$} & {$[0,083]$} \\
\hline \multirow{2}{*}{ Доля имеющих высшее образование } & $-0,301 * *$ & $-0,504 * * *$ & $-0,401 * * *$ \\
\hline & {$[0,070]$} & {$[0,074]$} & {$[0,057]$} \\
\hline \multirow{2}{*}{ Доля членов семьи пенсионного возраста } & $-0,511 * * *$ & $-0,671 * * *$ & $-0,577 * * *$ \\
\hline & {$[0,085]$} & {$[0,090]$} & {$[0,065]$} \\
\hline \multirow{2}{*}{$\begin{array}{l}\text { Доля членов домохозяйства с плохим } \\
\text { здоровьем }\end{array}$} & 0,078 & $-0,151^{*}$ & $-0,039$ \\
\hline & {$[0,074]$} & {$[0,082]$} & {$[0,057]$} \\
\hline \multirow{2}{*}{ Проживание в городе } & $-0,231 * * *$ & $-0,369 * * *$ & $-0,336 * * *$ \\
\hline & {$[0,089]$} & {$[0,077]$} & {$[0,071]$} \\
\hline \multirow{2}{*}{ 3-5 лет до смерти мужчины 21-60 лет } & 0,171 & $0,0859 * * *$ & $0,820 * * *$ \\
\hline & {$[0,274]$} & {$[0,082]$} & {$[0,077]$} \\
\hline \multirow{2}{*}{ 1-2 года до смерти мужчины 21-60 лет } & $0,841 * * *$ & $0,527 * * *$ & $0,666^{* * *}$ \\
\hline & {$[0,106]$} & {$[0,129]$} & {$[0,102]$} \\
\hline \multirow{2}{*}{ Год смерти мужчины 21-60 лет } & $-0,029$ & 0,027 & $-0,057$ \\
\hline & {$[0,162]$} & {$[0,171]$} & {$[0,107]$} \\
\hline \multirow{2}{*}{ 1-2 года после смерти мужчины 21-60 лет } & $0,399 * *$ & $0,0516^{* * *}$ & $0,477 * * *$ \\
\hline & {$[0,186]$} & {$[0,148]$} & {$[0,112]$} \\
\hline \multirow{2}{*}{ 3-5 лет после смерти мужчины 21-60 лет } & $-0,405$ & $0,470 * * *$ & $0,265 * *$ \\
\hline & {$[0,390]$} & {$[0,126]$} & {$[0,107]$} \\
\hline \multirow{2}{*}{$\begin{array}{l}\text { 3-5 лет до смерти члена семьи пенсионного } \\
\text { возраста }\end{array}$} & $0,0530 * *$ & $0,768 * * *$ & $0,760^{* * *}$ \\
\hline & {$[0,208]$} & {$[0,085]$} & {$[0,059]$} \\
\hline \multirow{2}{*}{$\begin{array}{l}\text { 1-2 года до смерти члена семьи } \\
\text { пенсионного возраста }\end{array}$} & $0,631 * * *$ & $0,0834 * * *$ & $0,815^{* * *}$ \\
\hline & {$[0,136]$} & {$[0,070]$} & {$[0,074]$} \\
\hline \multirow{2}{*}{ Год смерти члена семьи СТСВ } & 0,037 & $0,316^{* * *}$ & $0,202 * *$ \\
\hline & {$[0,143]$} & {$[0,100]$} & {$[0,086]$} \\
\hline \multirow{2}{*}{$\begin{array}{l}\text { 1-2 года после смерти члена семьи } \\
\text { пенсионного возраста }\end{array}$} & $0,338^{* *}$ & $0,360 * * *$ & $0,338^{* * *}$ \\
\hline & {$[0,135]$} & {$[0,083]$} & {$[0,077$} \\
\hline
\end{tabular}




\begin{tabular}{lcc|r}
\hline & $\begin{array}{c}\text { Модель 1 } \\
(2001-2010 \text { гг. }\end{array}$ & $\begin{array}{c}\text { Модель 2 } \\
(2011-2019 \text { гг. })\end{array}$ & $\begin{array}{c}\text { Модель 3 } \\
(2001-2019 \text { гг. })\end{array}$ \\
\hline 3-5 лет после смерти члена семьи & 0,196 & $0,306 * * *$ & $0,223 * * *$ \\
пенсионного возраста & {$[0,203]$} & {$[0,095]$} & {$[0,080]$} \\
Количество наблюдений & 7355 & 12242 & 20547 \\
Количество субъектов & 7355 & 12242 & 20547 \\
Количество переходов в бедность & 2084 & 3310 & 5848 \\
Логарифм псевдомаксимального & $-16567,70$ & $-25080,73$ & $-48856,26$ \\
правдоподобия & & & \\
\hline
\end{tabular}

Источник: Расчеты автора по данным РМЭЗ 2001-2019 г2.

Примечания: *, **, ***_значимость на 10, 5 и 1\%-ном уровне, в скобках приведены стандартные ошибки; д/х - домохозяйство; ТСВ - в трудоспособном возрасте; СТСВ - старше трудоспособного возраста.

Таблица П2. Факторы выхода домохозяйств из бедности (полупараметрическая регрессия Кокса)

\begin{tabular}{lcc|c}
\hline & Модель 1 & Модель 2 & Модель 3 \\
& $(2001-2010 г г)$. & $(2011-2019$ гг. $)$ & $(2001-2019$ гг.) \\
\hline Размер домохозяйства & 0,009 & $0,014 * *$ & $0,015^{* *}$ \\
Число детей в возрасте до 7 лет & {$[0,010]$} & {$[0,007]$} & {$[0,006]$} \\
Число детей в возрасте от 7 до 18 лет & $-0,093 * * *$ & $-0,056 * * *$ & $-0,051 * * *$ \\
& {$[0,031]$} & {$[0,019]$} & {$[0,019]$} \\
& $-0,038 * *$ & $-0,077 * * *$ & $-0,047 * * *$
\end{tabular}

Пол и возраст главы семьи (пропущенная переменная: глава семьи -мужчина ТСВ)

\begin{tabular}{|c|c|c|c|}
\hline \multirow{2}{*}{ Глава семьи - женщина ТСВ } & $-0,101 * * *$ & $-0,084 * * *$ & $-0,099 * * *$ \\
\hline & {$[0,018]$} & {$[0,019]$} & {$[0,011]$} \\
\hline \multirow{2}{*}{ Глава семьи - женщина СТСВ } & $-0,268 * * *$ & $-0,050 *$ & $-0,166 * * *$ \\
\hline & {$[0,041]$} & {$[0,029]$} & {$[0,027]$} \\
\hline \multirow{2}{*}{ Глава семьи - мужчина СТСВ } & $-0,201 * * *$ & $-0,063 *$ & $-0,149 * * *$ \\
\hline & {$[0,050]$} & {$[0,039]$} & {$[0,039]$} \\
\hline \multirow{2}{*}{ Доля работающих } & $0,373 * * *$ & $0,228 * * *$ & $0,297 * *$ \\
\hline & {$[0,047]$} & {$[0,036]$} & {$[0,033]$} \\
\hline \multirow{2}{*}{ Доля безработных } & $-0,256 * * *$ & $-0,175^{*}$ & $-0,235 * * *$ \\
\hline & {$[0,095]$} & {$[0,094]$} & {$[0,070]$} \\
\hline \multirow{2}{*}{ Доля имеющих высшее образование } & $0,196 * * *$ & $0,057 * *$ & $0,136 * * *$ \\
\hline & {$[0,040]$} & {$[0,026]$} & {$[0,026]$} \\
\hline \multirow{2}{*}{ Доля членов семьи пенсионного возраста } & $0,188 * * *$ & $0,052 *$ & $0,123 * *$ \\
\hline & {$[0,037]$} & {$[0,028]$} & {$[0,022]$} \\
\hline \multirow{2}{*}{$\begin{array}{l}\text { Доля членов домохозяйства с плохим } \\
\text { здоровьем }\end{array}$} & $-0,030$ & $-0,045$ & $-0,083 * * *$ \\
\hline & {$[0,032]$} & {$[0,034]$} & {$[0,026]$} \\
\hline \multirow{2}{*}{ Проживание в городе } & $0,117 * *$ & 0,018 & 0,050 \\
\hline & {$[0,057]$} & {$[0,021]$} & {$[0,033]$} \\
\hline \multirow{2}{*}{ 3-5 лет до смерти мужчины 21-60 лет } & $0,243 * * *$ & $0,159 * * *$ & $0,267 * * *$ \\
\hline & {$[0,092]$} & {$[0,030]$} & {$[0,045]$} \\
\hline \multirow{2}{*}{ 1-2 года до смерти мужчины 21-60 лет } & $0,361 * * *$ & $0,216 * * *$ & $0,330 * * *$ \\
\hline & {$[0,042]$} & {$[0,035]$} & {$[0,032]$} \\
\hline \multirow{2}{*}{ Год смерти мужчины 21-60 лет } & $-0,193$ & 0,021 & $-0,068$ \\
\hline & {$[0,128]$} & {$[0,077]$} & {$[0,070]$} \\
\hline
\end{tabular}




\begin{tabular}{|c|c|c|c|}
\hline & $\begin{array}{c}\text { Модель } 1 \\
(2001-2010 г г .)\end{array}$ & $\begin{array}{c}\text { Модель } 2 \\
(2011-2019 \text { гг.) }\end{array}$ & $\begin{array}{c}\text { Модель } 3 \\
(2001-2019 \text { гг.) }\end{array}$ \\
\hline \multirow{2}{*}{ 1-2 года после смерти мужчины 21-60 лет } & $-0,213^{*}$ & 0,033 & $-0,066$ \\
\hline & {$[0,121]$} & {$[0,058]$} & {$[0,053]$} \\
\hline \multirow{2}{*}{ 3-5 лет после смерти мужчины 21-60 лет } & $-0,166$ & $-0,027$ & $-0,010$ \\
\hline & {$[0,099]$} & {$[0,087]$} & {$[0,095]$} \\
\hline \multirow{2}{*}{$\begin{array}{l}\text { 3-5 лет до смерти члена семьи } \\
\text { пенсионного возраста }\end{array}$} & $0,0245^{* * *}$ & $0,231 * * *$ & $0,300 * * *$ \\
\hline & {$[0,070]$} & {$[0,018]$} & {$[0,026]$} \\
\hline \multirow{2}{*}{$\begin{array}{l}\text { 1-2 года до смерти члена семьи } \\
\text { пенсионного возраста }\end{array}$} & $0,351 * * *$ & $0,207 * * *$ & $0,298 * * *$ \\
\hline & {$[0,041]$} & {$[0,019]$} & {$[0,026]$} \\
\hline \multirow{2}{*}{ Год смерти члена семьи СТСВ } & 0,005 & $0,100 * * *$ & $-0,001$ \\
\hline & {$[0,052]$} & {$[0,037]$} & 0,035 \\
\hline \multirow{2}{*}{$\begin{array}{l}\text { 1-2 года после смерти члена семьи пенс. } \\
\text { возраста }\end{array}$} & 0,094 & $-0,032$ & 0,051 \\
\hline & {$[0,083]$} & {$[0,046]$} & {$[0,041]$} \\
\hline \multirow{2}{*}{$\begin{array}{l}\text { 3-5 лет после смерти члена семьи пенс. } \\
\text { возраста }\end{array}$} & $-0,029$ & $-0,022$ & 0,002 \\
\hline & {$[0,111]$} & {$[0,066]$} & {$[0,057]$} \\
\hline Количество наблюдений & 6525 & 4786 & 11964 \\
\hline Количество субъектов & 6525 & 4786 & 11964 \\
\hline Количество переходов в небедность & 4035 & 3638 & 8253 \\
\hline $\begin{array}{l}\text { Логарифм псевдомаксимального } \\
\text { правдоподобия }\end{array}$ & $-31182,49$ & $-27029,19$ & $-68603,83$ \\
\hline
\end{tabular}

Источник: Расчеты автора по данным РМЭЗ 2001-2019 г2.

Примечания: *, **, ***_значимость на 10, 5 и 1\%-ном уровне, в скобках приведены стандартные ошибки; д/x-домохозяйство; ТСВ - в трудоспособном возрасте; СТСВ - старше трудоспособного возраста. 